\title{
MUDANDO DE IDEIA: CRISTIANISMO EVANGÉLICO E FESTAS DE CAXIRI ENTRE OS NINAM DO ALTO MUCAJAÍ
}

Tainah Leite ${ }^{1}$

${ }^{1}$ Universidade Federal de Minas Gerais (UFMG), Programa de Pós-graduação em Educação (PPGE), Faculdade de Educação (FaE), Belo Horizonte, MG, Brasil

\section{Introdução}

A questão da transformação - e os modelos para pensá-la - tornou-se um tema caro e inescapável à antropologia do cristianismo, rearticulando de diferentes formas a dicotomia continuidade e mudança. A dupla constatação, tanto da inegável plasticidade do cristianismo e da habilidade de seus agentes de se moldarem a diferentes contextos culturais - os muitos cristianismos alternativos a partir dos quais a ortodoxia cristã se faz como síntese instável (Cannell 2005) - quanto da prevalência de uma retórica da conversão que enfatiza a ruptura radical que o cristianismo introduz com a tradição (Robbins 2007; Engelke 2004; Meyer 1998), faz das etnografias de diferentes expressões do cristianismo e de processos de cristianização um importante mote para uma discussão mais abrangente sobre mudança cultural (Robbins 2004; Vilaça 2016).

Paralelamente, a transformação é também um tema caro à etnologia ameríndia, impondo-se desde a própria imaginação nativa (Gow 2001; Viveiros de Castro 2012). A discussão sobre mudança cultural, quando transposta para a Amazônia indígena, vê-se assim complexificada pela dificuldade em se falar de continuidade ou ruptura entre povos que atribuem um alto valor à relação com o exterior, frequentemente considerado a fonte das forças produtivas (conferir, dentre outros, Levi-Strauss 1993; Viveiros de Castro 2002a; Overing \& Passes 2000:20-22; Carneiro da Cunha 2009:461). Mas se o modo característico de perpetuação das socialidades amazônicas é a transformação, faz-se necessário matizá-las a partir de descrições etnográficas que permitam explorar as "zonas de ambiguidade entre continuidade e descontinuidade" (Fausto 2007:75). 
Com estas questões em mente, o que se segue é parte de um intento de vislumbrar o que seria um modo ninam de conceitualizar e experimentar diferentes transformações, em função da aproximação etnográfica com a relação que estes lograram estabelecer com o cristianismo evangélico e os missionários cristãos. ${ }^{1}$

\section{Os Ninam, os missionários (e o caxiri)}

Os Ninam são um povo do Norte amazônico que se reconhecem e são reconhecidos como integrantes de um conjunto étnico mais amplo, os Yanomami - conjunto que agrega também os Sanöma, Yanomae, Yanomama e Yanomami (ou Yanomãmi, Shamatari) - e falantes de língua de mesmo nome também da família Yanomami. Habitando a fronteira oriental do território tradicionalmente ocupado por estes povos - sobretudo a calha do rio Mucajaí (Ninam Central ou Xilixana) e a região do rio Uraricacaá e Ericó (Ninam do Norte ou Xiliana), no estado de Roraima, e do rio Paragua, na Venezuela - os Ninam foram um dos primeiros grupos Yanomami a serem contatados por agentes não indígenas, em parte devido à sua localização próxima às rotas utilizadas pelas primeiras expedições em seu território, vivendo hoje em zona fronteiriça a muitos projetos de colonização agrícola promovidos pelo Estado brasileiro (Le Torneau 2003).

A pesquisa de campo que dá origem a este trabalho foi realizada junto às aldeias ninam do Alto Mucajaí, formadas por reminiscentes e descendentes dos grupos identificados como Kasilapai e Pola theli que habitavam a região quando, em 1958, missionários canadenses vinculados à missão interdenominacional Unevangelized Field Mission (UFM) ali aportaram acompanhados de dois guias waiwai. Este contato foi o resultado de dois movimentos expansionistas: dos Ninam, que haviam inclusive empreendido arriscadas viagens de canoa rio abaixo mas sem sucesso no estabelecimento de novas alianças, e dos missionários e Waiwai em busca dos "grupos não alcançados". Tal aspecto certamente contribuiu para que o grupo formado por Neil Hawkins, John Peters, Marawenare e Mawasha fosse bem recebido pelos Ninam, de sorte que os missionários lograssem estabelecer ali um posto permanente de contato, que desde então, exceção de alguns curtos períodos, sempre contou com missionários residentes. Desde 1970, o posto missionário do Alto Mucajaí encontra-se vinculado à Missão Evangélica da Amazônia (Meva), sediada em Boa Vista.

O cenário que se nos apresenta é assim o de uma "longa conversação" (Comaroff \& Comaroff 1997) entre os Ninam e os missionários, baseada 
na interação cotidiana e mediada por diferentes trocas, tanto quanto na atividade explícita de proselitismo, que resultaram em uma série de transformações relevantes. Apesar disso, os Ninam não se apresentam necessariamente como cristãos e/ou crentes e também não se deixam apreender como tais. Isto não impede entretanto que (alguns dentre) os Ninam se reconheçam como crentes ou que sejam reconhecidos como tal em contextos específicos. Apesar das transformações de que trataremos adiante, não estamos diante de um quadro de "cristianização", ou talvez estejamos, considerando quão variadas podem ser as expressões particulares de um tal fenômeno, mas este não será o foco de nossa discussão. A pergunta "os Ninam se converteram?" deixamos para os missionários.

Importa, contudo, destacar que o cristianismo, seus ritos, discursos e agentes são parte importante da tessitura do cotidiano na região: uma parcela considerável da população de diferentes aldeias do Alto Mucajaí assiste aos cultos dominicais realizados no aglomerado da "Missão" - uma das seis aldeias da região do Alto Mucajaí e que chamo de aglomerado misto porque reúne residências ninam e missionárias; muitos homens adultos estão ou estiveram envolvidos no trabalho de tradução da Bíblia; afora a presença constante dos missionários que fez deles aliados preferenciais e a principal fonte de conhecimento dos Ninam sobre os klaiowá (não indígenas) e seu mundo. Significativamente, a frequência aos cultos, por exemplo, era algo da ordem das atitudes convencionais acerca das quais qualquer indagação sobre a sua razão de ser encontrava como resposta um lacônico "inaha yamak apè tha wei" - "é assim que nós fazemos". Se digo, portanto, que os Ninam não se apresentam como cristãos, é também porque ser crente não é usualmente um traço distintivo relevante entre/para eles. E isto já nos diz algo sobre a modulação particular do cristianismo ali.

Entretanto, o quadro é ligeiramente diverso quando se leva em conta outro aspecto central no cotidiano do Alto Mucajaí: as bebedeiras de caxiri, ou haklauko. É em relação a este contexto que ser crente (ou não) pode se tornar um traço relevante, bem como as variações possíveis de não ser mais crente, de pretender virar crente etc. Desde os meus contatos iniciais com os Ninam estive interessada no modo como eles experimentavam e elaboravam conceitualmente a relação com os missionários e o cristianismo. O caxiri, entretanto, foi surgindo reiteradamente em nossas conversas, enquanto suas festas se faziam contexto privilegiado e frequente de minha interação com os Ninam, do mesmo modo que se infiltrou na socialidade ninam, sendo hoje um de seus principais combustíveis, movimentando a produção e o consumo de roças, falas, pessoas, festas e mortos. 
Apesar desta centralidade, o consumo da cerveja de mandioca espraiado entre diferentes populações indígenas sul-americanas - é um hábito recentemente incorporado. De fato, até a metade do século XX não há registros de que os Ninam, ou qualquer outro grupo Yanomami, fizessem uso de alguma bebida fermentada. Embora haja uma certa variação nas versões sobre sua introdução, os Ninam do Mucajaí parecem concordar que foi entre fim dos anos 1960 e início dos anos 1970, durante uma viagem ao Palimi-ú, região Yanomam no Alto Uraricoera, que os homens ninam conheceram o caxiri. Eles lá estavam acompanhando os missionários na abertura de uma nova pista de pouso neste que se constitui como o segundo posto da Meva em território Yanomami. Os Palimitheli, por sua vez, haviam se iniciado no consumo do caxiri através de uma rede de contatos que os conecta com grupos Caribes do maciço guianense. Após a temporada no Palimi-ú, alianças foram consolidadas entre estes dois grupos e, junto com novas esposas e cunhados, o caxiri - batizado de haklauko (hakla-mandioca brava; -uko: suco/sumo preparado à base de algum vegetal) - se espalhou pela região do Alto Mucajaí e mais além. ${ }^{2}$

Como não ter a atenção capturada por esta curiosa e irônica coincidência que correlaciona o contato missionário e a introdução de um ritual de beberagem? Ironia acentuada pelo modo como os Ninam pareciam tomar o cristianismo em continuidade com a tradição nativa enquanto a introdução da bebida indígena era marcada como uma transformação. Contrastando com o acento de traço costumeiro que recebe o cristianismo, as pessoas frequentemente assinalavam o fato de que o haklauko é uma bebida dos outros (ai theli uko): não é nossa cultura, ${ }^{3}$ diziam alguns Ninam em português.

Com efeito, o consumo do haklauko e o cristianismo eram contrapostos de maneira contundente tanto pelos missionários quanto pelos Ninam em conversas informais, prédicas, falas cerimoniais, etc. Não obstante, a maneira como cada qual concebia esta oposição não era a mesma e é justamente este modo diferenciado de se verter esta oposição que gostaria de explorar aqui, articulando-o ao modo também diferenciado como Ninam e missionários concebem suas próprias transformações. A trama que conecta o cristianismo e as bebedeiras de caxiri, os Ninam e os missionários apresenta-se assim como um contexto privilegiado para vislumbrar dois modelos diferenciados de transformação em relação. E, no contraste entre eles, o modo próprio ninam de pensar/experimentar transformações pode ganha maior saliência.

Trabalhemos aqui com a hipótese de que a importação do caxiri pouco após a chegada dos missionários não é mero acaso - exercício imaginativo, em que a perspectiva diacrônica da introdução do haklauko e do encontro missionário é menos relevante do que a possibilidade de se perceber na 
tensão sincrônica entre eles a atualização de uma dialética constituinte da socialidade ninam entre modos de ação convencionalizantes e moralizantes e modos de ação pautados pela alteração e a disrupção. ${ }^{4} \mathrm{O}$ que pretendo destacar é como estas duas vias de transformação percorridas pelos Ninam as bebedeiras de caxiri e o cristianismo, cada qual articulando à sua maneira continuidade e mudança - são relacionadas em uma mesma estrutura que informaria o modo próprio ninam de experimentar e criar um mundo continuamente transformacional.

Iniciarei esta exploração apresentando as modulações específicas que o cristianismo assume entre os Ninam e também uma breve etnografia dos modos de beber no Alto Mucajaí para, em seguida, explicitar as diferenças entre a perspectiva missionária e a ninam sobre esta oposição, tendo por foco a construção do caxiri como um "problema" e do cristianismo como seu "controle". Por fim, buscarei destacar como estas questões podem ser apreendidas também a partir da aproximação com a noção de conversão e sua tradução entre os Ninam como pihi yapa lamowei.

\section{Pastor pèk e a boa fala de Teus}

Nas conversas sobre o virar crente/crentelayohe entre os Ninam, encontramos alguns elementos recorrentes sugestivos do lugar ocupado pelo cristianismo evangélico entre eles. Os Ninam contam que, ao ouvirem os missionários falando sobre a palavra de Deus (Teus e thã), pensaram: "muito bem! é boa essa fala", e então começaram a frequentar os cultos (ai amowei). Esta sequência - ouvir a palavra de Deus, pensar que ela é boa, frequentar os cultos - está presente tanto nos relatos das pessoas mais velhas quando se referem ao encontro com os missionários pioneiros quanto no relato de jovens que nasceram e cresceram em contato com os missionários ao narrarem sua adesão ao cristianismo. Ela revela um entendimento comum de que esta adesão relacionar-se-ia a um determinado tipo de escuta e disposição subjetiva em face de Teus e thã e da participação em certos rituais, notadamente os cultos dominicais.

Os cultos são chamados entre os Ninam de aiamowei, que pode ser traduzido como "cantar cantos outros", ou "cantar cantos dos outros". Um dos meus anfitriões referia-se a seu sogro já falecido como pastor e, ao me explicar o que isto significava, destacava que ele sempre fazia com que todos cantassem aos domingos. Noto que, contrariando a perspectiva dos missionários que lamentavam a não conversão dos Ninam do Alto Mucajaí, apontando como atestado deste "fracasso" o fato de que não 
havia ali igrejas ou pastores, os Ninam, quando querem falar daqueles dentre eles que seriam crentes, dizem pastor pèk (o povo pastor), estendendo a alcunha indistintamente. Recordo também de uma jovem que, ao ser interpelada sobre o que era Complei (Conselho de Pastores e Líderes Evangélicos Indígenas), respondeu sem titubear: $\underline{\text { música }}$ - provocando a risada de todos. Em sua comicidade, esta anedota é significativa da estreita associação entre cristianismo e cantos, pois se a experiência cristã entre os Ninam é largamente baseada na assistência aos cultos, estes por sua vez são bastante centrados nos cantos.

Os cantos evangélicos são chamados de aiamo thã (ai- outro; Amo thã é como os Ninam se referem aos cantos entoados nos festivais funerários yãimowei) e são usualmente traduções para a língua ninam de hinos evangélicos, reunidos em um pequeno hinário impresso e entoados seguindo o mesmo estilo melódico. A ênfase nos cantos faz com que os cultos sejam reconhecidos por sua alegria. Em sua maior parte, os aiamo thã podem ser caracterizados como hinos de louvor - Teus totihi pè haikia (Deus é mesmo bom), dizia um dos mais cantados.

Conversando com algumas pessoas que não residiam mais no Alto Mucajaí - e assim não frequentavam mais os cultos - elas se recordavam nostálgicas de como era bom quando todos cantavam juntos e não homens e mulheres separadamente como nos festivais funerários yãimo, o principal ritual tradicional ninam. Frequentar os cultos e cantar todos juntos propiciam entre os presentes um certo estado de felicidade: apè xihole. Xihole é também como fica alguém ao se lembrar de um presente recebido e da pessoa que o ofertou, por exemplo. É um estado de felicidade próximo à gratidão e que se relaciona à efetivação de relações apropriadas de cuidado e generosidade, sobretudo entre parentes e corresidentes. Gow (2006:231-232) também notava entre os Piro a preponderância dos cantos para a descrição do cristianismo evangélico. Semelhante ao que percebemos entre os Ninam, Gow sugere que os cantos possibilitavam ocupar uma posição subjetiva específica: mais do que celebrando a fé, eles seriam o modo mesmo de se tornar cristão.

Além dos cantos, os cultos entre os Ninam são marcados por admoestações que visam manter uma vida tranquila. Quando os missionários dizem Teus e thã, traduzindo como "Palavra de Deus", o referente é sempre a Bíblia. Os Ninam, contudo, incluem também muitos destes discursos, sejam eles feitos pelos missionários, ou pelos próprios Ninam. Um homem adulto ninam, que trabalhava eventualmente como tradutor e informante junto aos missionários, me apresentou o seguinte resumo sobre a fala de Teus, que não se restringe a preceitos bíblicos, mas é uma coleção de recomendações morais e orientações de conduta: 
A fala de Teus é assim: "Não faça coisas erradas. Você deve agir corretamente. Você não deve bater em outra pessoa. Não deve fazer coisas ruins para outras pessoas. Não roube as mercadorias dos outros. Assim é a palavra/fala de Teus. Não tenha relações sexuais com outra mulher. Não transe com outra mulher, só com sua mulher". Assim é a palavra de Teus. "Se você tiver relações sexuais com outra mulher, seu peito vai ficar sujo"5 - Teus disse. (A. Xilixana, 2013. Tradução para o português da autora).

A "fala de Teus", assim apresentada como coleção de interdições e preceitos de conduta, resulta bastante semelhante aos discursos realizados pelos pata thepe, os homens e mulheres mais velhos, em contextos de admoestação, no alvorecer nas malocas ou antes de iniciar uma bebedeira de caxiri, quando eles então dão orientação aos jovens (miyao mowei). E, de fato, ao comentarem sobre seu contato com a mensagem missionária, os Ninam concluem: "Haikia. Teus e thã apé totihi" (Está certo! A fala de Teus é boa!), assim expressando também que a fala de Deus está, em larga medida, em conformidade com suas próprias "falas corretas" - "kama e thã xaali yai" (nossas falas corretas), que seriam as falas dos anciões/pata thepe sobre a maneira apropriada de se portar.

Sobre estas falas ditas também patamou entre os Yanomami, Alès (2006:167-169) destaca como elas visam propiciar um sentimento de pertencimento, perseguindo um ideal de paz que implica continuar vivendo no mesmo lugar e que, para realizar-se, depende muitas vezes do apelo aos membros mais jovens para abandonar comportamentos potencialmente disruptivos: o roubo de roças, as relações extraconjugais etc. Carrera (2004) nota também como os discursos patamou têm um caráter generativo de relações apropriadas. Estas mesmas características podem muito bem ser atribuídas ao cristianismo entre os Ninam.

Com pouca ênfase em seus aspectos transcendentais, o cristianismo é assim destacado por seus aspectos moralizantes. ${ }^{6} \mathrm{O}$ código de conduta ressaltado a partir de Teus e thã contribui para o estabelecimento de relações apropriadas entre parentes e aliados: o roubo, o adultério, a fofoca, as brigas e as bebedeiras são atitudes condenadas pelo cristianismo e que os próprios Ninam consideram que devem ser evitadas, a fim de que se possa viver bem. O cristianismo entre os Ninam coincide, deste modo e em larga medida, com o lugar da moralidade do entre si, tal como prefigurada nos discursos dos pata thepe.

O modelo de realização do crente ninam seria o de uma pessoa-entreparentes, na direção do estabelecimento de uma "comunidade de similares" (Overing 1999). O cristianismo é extremamente eficaz e potente neste sentido, permitindo que as pessoas se relacionem de forma a apagar certas 
distinções operantes mesmo entre corresidentes, como aquelas de gênero e geração. Recordemos que diferentemente do que ocorria nos contextos tradicionais ninam, no espaço delimitado pelo cristianismo, homens e mulheres cantavam juntos e o espaço de fala podia ser ocupado também pelos jovens. Os Ninam obliteravam ainda as distinções presentes no cristianismo ao tratarem todos os crentes como pastores, por exemplo. O cristianismo inova ao permitir que certas convenções morais - que de outra forma poderiam apenas ser provocadas ou eliciadas através de um uso criativo - possam ser acionadas de forma direta e explícita. Uma mesma admoestação de que não se deve roubar as roças, por exemplo, feita fora do contexto do cristianismo, pode ter o efeito reverso de levar a conflitos e trocas de acusações. Os rituais cristãos se revestem assim de uma certa infalibilidade na constituição de uma comunidade de similares e permitem expandir este ideal de sociabilidade para além do conjunto de corresidentes.

Se é bem provável que o interesse inicial dos Ninam pelo cristianismo tenha se dado por aquilo que o fazia diferente de tudo que eles conheciam o próprio fato dos cantos ai amothã serem outros, tão diversos em estrutura, conteúdo e performance dos cantos tradicionais, além da própria associação com os missionários e o exterior - ele hoje parece ser sobretudo um instrumento para a realização de um ideal moral e, neste sentido, mesmo suas inovações são colocadas ao lado da continuidade e da reprodução da socialidade ninam. Um tal quadro, em que os aspectos de transformação que o cristianismo acarreta entre os Ninam é obviado, encontra sua razão de ser em sua articulação a certos aspectos da socialidade ninam, que carregariam, eles sim, a marca da alteridade e alteração. Refiro-me aqui especialmente às bebedeiras de caxiri e tudo que se derrama delas.

\section{Haklauko: modos de beber}

As bebedeiras de caxiri, em um sentido forte, são eventos que significam o auge da sociabilidade no Alto Mucajaí, congregando pessoas de distintas aldeias em uma única casa. Há conversas, trocas, músicas, brincadeiras, danças, namoros... e por vezes estes eventos são chamados festas. Há muitas ocasiões propícias ao haklauko. Nas diferentes comunidades e casas do Alto Mucajaí bebe-se quando da realização de algum trabalho coletivo derrubada de roças, construção de casas etc. - e o haklauko é então dito pagamento (noa). Bebe-se muito durante todas as etapas dos grandes festivais funerários yãimowei, bem como para recepcionar os homens da casa após alguma viagem ou caçada prolongada. Bebe-se para fazer reunióes e 
patamou e discutir algum assunto de interesse coletivo e, ainda, bebe-se também à toa, quando a produção de macaxeira é abundante.

São as mulheres as responsáveis pelo preparo do haklauko, desde o cuidado com a roça até o serviço durante as bebedeiras. São elas as donas da bebida, imprimindo-lhe sua marca (mayo) e emprestando-lhe o nome: Alzira e haklauko, Aspili e haklauko, Silvana e haklauko etc. O preparo do haklauko entre os Ninam envolve o cozimento e posterior mastigação da polpa da macaxeira. A massa mastigada com aspecto de mingau é deixada em panelas ou grandes vasilhames de plástico próxima ao fogo, repousando. O tempo de repouso é determinante para o grau de fermentação e teor alcoólico da bebida, e também compete às mulheres controlar esse tempo, produzindo um caxiri doce (haklauko kethethe), consumido após um ou dois dias em contextos mais familiares, ou um caxiri forte (haklauko naxi) com maior teor alcoólico - usualmente não marcado, considerado o verdadeiro - após três ou quatro dias de fermentação, podendo chegar-se até mesmo a uma semana em caso das festas yãimo.

Os homens, por sua vez, são os responsáveis pelos convites. A abrangência do círculo de convidados depende da razão suplementar da bebedeira e da quantidade de haklauko disponível, mas usualmente são os afins de comunidades próximas - sogros, cunhados, genros; efetivos ou classificatórios - os convidados para o trabalho coletivo ou para as grandes festas podem ser aqueles aliados de comunidades mais distantes, e há alguma reciprocidade não ordenada entre os convites. Já as bebedeiras à toa ocorrem geralmente em um círculo mais restrito de consanguíneos e afins aparentados pela corresidência. Se tomado o conjunto de todas as casas do Alto Mucajaí e as diferentes modalidades de beberagem, pode-se dizer que as bebedeiras de caxiri ocorriam quase diariamente, em especial na época de seca (outubro a abril), e algumas vezes com mais de uma acontecendo no mesmo dia, com as pessoas deslocando-se de uma casa a outra. Ir atrás do caxiri, como dizem os Ninam em português, é uma atividade regular, e pode-se eventualmente ir longe, viajando algumas poucas horas de barco para as comunidades mais distantes. O consumo do haklauko envolve necessariamente a desmedida: beber só um pouco ou beber sem ficar bêbado - ainda que seja preconizado por alguns pata thepe - não é uma alternativa real.

Homens e mulheres usualmente iniciam o caxiri em grupos à parte, mas há conversas e brincadeiras de um grupo para o outro. Quanto mais a cuia com caxiri e sua dona circulam, mais próximas as pessoas ficam. Quando sob o efeito do caxiri, a conversa é sempre com os dois interlocutores muito próximos, às vezes testa com testa e braços sobre os ombros. As mulheres que iniciaram o serviço em silêncio, sem sequer dirigirem o olhar a seus 
convidados, depois de muitas rodadas de caxiri podem então brincar e, enquanto seguram o braço de alguém e invariavelmente derramam alguma porção da bebida, dizem entre risos: "Você ainda não está bêbado? Será que meu caxiri está fraco?!". Perguntar: "Você já está bêbado?" (wa nomayo ha?) é uma forma usual de iniciar uma nova conversa.

Após algumas rodadas de haklauko, mais contextos de interação vão sendo sobrepostos. É especialmente comum que as bebedeiras sejam utilizadas como espaço para patamou, quando planos e decisões coletivas são orquestrados, em geral no início das reuniões, antes que todos fiquem muito bêbados. As pessoas aproveitam a audiência propiciada pelo haklauko para contar histórias interessantes: o relato de visitas a outras aldeias distantes ou mesmo a cidades estão entre aqueles que mais prendem a atenção dos ouvintes, mas também narrativas míticas (pata pèk e thã) são contadas neste contexto. As sessões de caxiri são propícias para diferentes brincadeiras. Estas são principalmente uma forma de distender os laços de parentesco, colocando em primeiro plano e de maneira jocosa relações potenciais que costumam ser eclipsadas: esposos classificatórios - em especial quando já em idade madura - às vezes fazem piadas com suas esposas classificatórias, ou simplesmente as chamam em voz alta de esposa (patasi) para risada de todos.

Sessões de xamanismo podem ser realizadas durante a bebedeira caso alguém - crianças, principalmente - esteja doente. Na verdade, o caxiri parece despertar xamãs (xapolis) que em outros contextos são pouco ativos, embora seja negada qualquer relação do haklauko com os hikala pék (espíritos auxiliares do xamã), que têm como substância preferida a yãkiana. É também durante uma bebedeira de caxiri que diferentes "rituais" de origens diversas costumam acontecer: o tradicional corte de cabelo das meninas recém-púberes; a furação do braço dos caçadores com rabo de arraia para não ficar panema - uma prática aprendida com outros grupos Yanomami; a tintura dos cães de caça com feitiço propiciador etc. Note-se que o caxiri não seja feito para isso: cortar o cabelo, furar o braço ou tingir o cachorro não estão entre as razões possíveis de serem elencadas ao convidar alguém para o caxiri, mas sim que o caxiri é o gatilho que dispara esta espécie de efervescência ritual.

Uma sessão de caxiri realmente boa deve acabar em dança de pares, como um forró, e namoros noite adentro, com uma sobra de haklauko para ser servida como desjejum. Se o caxiri for pouco ou estiver fraco/doce, as pessoas vão embora tão logo ele acabe, muitas vezes reclamando pelo caminho que alguns dos anfitriões estavam tomando o haklauko escondido, que falaram seu nome à toa, que isto ou aquilo não estava certo. Estas conversas nas voltas do caxiri são reveladoras de tensões latentes que marcam toda a festa. 
O caxiri é entre os Ninam bebida de muitos atributos e veículo de muitos afetos: serve à ressocialização daqueles que estiveram ausentes; é dito "pagamento" quando servido após o trabalho coletivo; faz desaparecer a timidez; é dádiva e contradádiva que reafirma alianças. Os festivais funerários yãimowei seguem sendo o grande nexo articulador da socialidade ninam, mas entre uma grande festa e outra há inúmeras bebedeiras de caxiri. Uma casa onde está sendo servido o haklauko contrasta fortemente com o cotidiano de uma casa sem haklauko: ele agrega pessoas que de outro modo estariam dispersas em vários espaços com afazeres distintos (cuidando de suas roças, caçando, lavando roupas, coletando bacaba etc.) e permite atualizar relações que usualmente não são acionadas. Ele reúne também pessoas de outras casas, colorindo a interação com um clima de alegria e extravasamento - as visitas realizadas sobriamente não se comparam aos encontros regados a muitas cuias de haklauko.

Mas seguindo esta linha da sociabilidade em ebulição, o caxiri é também uma força de disrupção. Os mesmos elementos de intensificação da sociabilidade-brincadeiras, dança, patamou, conversas - podem ser o atalho para conflitos e brigas. Lampejos desta ambiguidade atravessam toda a bebedeira: reclamações sobre o serviço demorado; críticas em tom de brincadeira ao fato de que os parentes foram apenas para beber e não para trabalhar; reclamações no caminho de volta. Nas palavras de um dos pata thepe, o caxiri atrai quem antes foi dividido, e se havia uma razão para essa divisão - conflitos latentes envolvendo casamentos desfeitos, ciúmes entre irmãos etc. - há de se adivinhar a ambiguidade dessa atração. O haklauko é força centrípeta que leva a alegria da vida em comum a seu limite, revelando-se também força centrífuga quando esta efervescência atinge seu paroxismo - a raiva - em um campo semântico relacionado frequentemente ao luto - colocando em xeque a delicada arte de como viver junto. ${ }^{7}$

Quase toda bebedeira de caxiri resvala em brigas de intensidades e abrangências variadas. Digo resvala, mas não parece que as brigas sejam algo incidental, mas parte mesmo do movimento das bebedeiras. Em muitas das festas em que estive presente, em algum momento, uma pessoa próxima me aconselhava a ir embora, dizendo simplesmente que iriam começar a brigar - como se este fosse o movimento previsto independente de razões muito claras para a briga. Um dos efeitos do caxiri - explicava-me um dos xamãs, diferenciando-o da yãkiana - é justamente fazer com que as pessoas fiquem mais valentes (waithilimowei) e queiram brigar.

O campo semântico de waitihili, que aqui traduzo como valente, seguindo os Ninam, é bastante amplo, relacionando qualidades como coragem, valentia, generosidade, humor e estoicismo, remetendo, por 
fim, a um ideal de realização da pessoa moral ninam. De um modo geral, a disposição waithili é valorizada entre os Ninam, inclusive entre as mulheres, quando são capazes de "falar forte" e de se fazer ouvir. Mas é importante destacar que cada esfera de relações impõe um tipo de comportamento considerado adequado, seguindo valores morais divergentes e articulados: um homem que se mostra excessivamente agressivo ou pouco generoso entre os seus parentes é tão desprestigiado quanto aquele que se mostra covarde entre inimigos. É por isto que o waithilimowei - esta disposição para a briga - no contexto das bebedeiras de haklauko era normalmente depreciado ou lamentado. Por mais apreciadas, aguardadas e celebradas que sejam as bebedeiras de caxiri, elas são constantemente - se não sempre - lembradas pelo viés das brigas, o que faz do haklauko também um problema.

\section{Inventando o caxiri como problema e o cristianismo como controle}

O "problema do caxiri" era um tópic recorrente entre os Ninam e os missionários. Teus e thã e os discursos dos pata thëpe em suas arengas matinais coincidiamm em reforçar que as pessoas não devem brigar, falar mal dos outros e, em especial, que as pessoas não devem beber. A oposição entre Teus e thã - a palavra de Teus apreendida a partir de seu conteúdo moral - e o haklauko era explicitamente marcada, seja nos cultos, ou em conversas informais, reuniões e nas próprias sessões de caxiri.

No entendimento missionário, a permissividade sexual e as brigas, ambas potencializadas pelo haklauko, seriam os principais aspectos da socialidade ninam que impediriam a conversão e a realização de uma vida cristã. Até mais do que o xamanismo, era o consumo do haklauko - e as festas funerárias, sobretudo por serem um momento de consumo elevado da bebida - o alvo preferencial das prédicas missionárias que justificavam sua oposição, também relembrando que o hábito não era parte da "cultura tradicional". Mas é justamente a possibilidade de o cristianismo se colocar como mecanismo de controle destes aspectos que os missionários reconhecem como um atrativo para os Ninam - e que a insistência com que condenavam o haklauko tornava a mensagem cristã relevante entre eles. "Relevância" é um conceito utilizado pelos missionários para explicar a adesão à mensagem cristã e "está ligada à maneira com que o evangelho apresenta soluções para os problemas, conflitos e limitações da população-alvo da pregação evangélica" (Santos \& Montes 
2011:25). A mensagem missionária esforçava-se assim para inventar o caxiri como problema, ao mesmo tempo em que apresentava a adesão ao cristianismo como solução.

Mas esta relação entre o cristianismo e o haklauko também era acionada pelos Ninam. Em diversas reuniões e patamo, as pessoas repetiam que era preciso ter controle, beber com controle ou lamentavam que as pessoas (Ninam) bebiam sem controle. Resumindo: era preciso controlar o caxiri, implicando aí minimizar seus efeitos disruptivos, traduzidos sobretudo nas brigas. E era exatamente como um dos controles preferencias do caxiri que o cristianismo parecia encontrar seu lugar, colocado como uma espécie de ancoradouro moral e/ou horizonte transformacional possível para aqueles que não são crentes sempre que tensões e conflitos derivados do caxiri acentuavam-se. Meus anfitriões, por exemplo, diante de tensões crescentes no círculo de corresidentes em que eclodiam brigas a cada sessão de haklauko, conversavam entre si dizendo que estavam pensando em virar crentes para, quem sabe assim, diminuir o caxiri e poderem viver bem.

Quando falamos do ideal de bem-viver entre os Ninam nos referimos a um certo modo de vida harmonioso - sem brigas, mentiras ou "traições", da "sociedade tranquila", em que todos compartilham de uma mesma disposição subjetiva pihi xihole que identificamos também nos cultos cristãos. Este ideal está ancorado em um estado da pessoa subsumido à expressão themi e que os Ninam articulavam ao âmbito de uma vida saudável. É importante notar que a noção de saúde expressa por themi não se relaciona direta ou exclusivamente a doenças, mas à produção de novas pessoas. Uma pessoa saudável é sobretudo aquela apta a engajar-se no processo de produção de parentesco que relaciona alta realização moral e produtividade (ver Overing \& Passes 2000 para uma associação entre fertilidade e alta realização moral.) Themi é utilizado pelos Ninam também para referir-se ao estado do crente quando alcança o céu em seu destino póstumo e expressa a ressurreição e a reconstituição dos corpos ao mesmo tempo em que há a harmonia da vida social celeste, acionando no interior do cristianismo esta correlação entre corporeidade e moralidade.

Themi é oposto ao estado de embriaguez - em especial, o estado de embriaguez propiciado pelo caxiri - podendo ser então traduzido como sóbrio. E assim o é justamente porque a embriaguez de caxiri é identificada com um estado de alteração oposto à moralidade do parentesco e à produção de um sentido de "comunidade de similares". Este era o grande problema do caxiri desde a perspectiva ninam e que não se confina a uma dinâmica interna ao cristianismo. 
Gow (2001) descreve como os encontros regados a cerveja entre os Piro, guiados por um sentimento de euforia meyinlu, são simultaneamente marcados pela "latente hostilidade" entre convidados e anfitriões, já que claramente estes "não 'vivem bem' uns com os outros: se o fizessem, eles viveriam juntos" (Gow 2001:141). Os convidados são outros e não parentes, ainda que estejam se comportando como parentes, e a cerveja ali pode tanto relaxar estas tensões como exacerbá-las, fazendo com que a festa termine em briga. As brigas tenderiam assim a reforçar a distinção entre um nós aqueles com os quais se vive bem - e os outros. Mas a violência efervescente do haklauko ninam não é do tipo que manifesta relações estruturadas pelo contraste entre um nós e um eles, mobilizando as categorias de afinidade e outros ordenadores sociais. Ao contrário, ela desfaz e borra estes limites, eclodindo muitas vezes no interior do domínio da corresidência e mesmo da consanguinidade.

Por vezes, diante da iminência de uma briga, os parentes mais próximos - mãe, pai, e mais usualmente, irmãs ou irmãos - irão segurar o valente gritando-lhe: "Aqui não tem outros. Não pode brigar. Chega!" (ai theli kii ape lãle. xitiomei pemi. inaha kuop). É preciso lembrar ao bêbado que ele está entre parentes e que ali não há outros, pois o caxiri faz com que uma pessoa desconheça os seus. Se os Ninam fazem questão de marcar que o caxiri é uma bebida dos outros - ai theli uko, diziam - este genitivo remete não apenas à origem da bebida, mas também ao vetor transformacional que ela acarreta. Se o caxiri faz com que uma pessoa desconheça os seus - vendo- os como outros - é também porque ele faz com que alguém vire outro. Ao dizerem dos efeitos do haklauko, os Ninam reforçam que ele não só faz ficar "valente" e querer brigar (waithilimowei), como pode levar alguém a virar outro (ai thelimowei). Ai theli refere-se especialmente às outras gentes, de outras comunidades com as quais não se tem relação e/ou se tem relação de hostilidade; inimigos seria uma tradução possível.

Os efeitos do haklauko são descritos como mudanças que afetam sobretudo o pihi de uma pessoa, a sede dos pensamentos, volições e afecções. Se, antes mesmo de beber, a pessoa já estiver em um estado triste, chateado ou de luto (pihi walihik, pihi xoãli etc.), a ação da bebida pode ser ainda mais potente e incontrolável. Isto porque estes são estados que já denotam um afastamento do estado normal de uma pessoa, "normalidade" que é marca e atestado do compartilhamento de perspectiva com os seus, no contexto de produção do parentesco. É por referência ao pihi que os Ninam expressam o compartilhamento - ou a mudança - de perspectivas, sendo o locus de confluência do conhecimento, disposições morais e afetos que regem as relações intersubjetivas. A perspectiva sobre o mundo deve ser assegurada 
tanto pelas relações que a sustentam quanto pelo corpo que a produz. O haklauko altera uma e outra.

O haklauko é, como o cauim tupi, um antialimento (Viveiros de Castro 1986:346). Enquanto o chibé, o beiju, o caribé de banana etc. contribuem para a produção de corpos semelhantes, ou seja, para corpos de parentes, confirmando que aqueles que comem juntos compartilham de uma mesma perspectiva, o haklauko altera significativamente estes corpos e disposições. Ao trazer à tona um coeficiente de alteridade nos menores intervalos das relações - entre pai e filho ou mesmo entre irmãos - o caxiri expõe o limite e a fragilidade da identidade em um universo de perspectivas em disputa. Assim como a feitiçaria em outros contextos etnográficos (Vanzolini 2015), o caxiri aponta para a reversibilidade e os limites da produção de parentesco, revelando o outro/inimigo que persiste naquele que foi feito parente (ver Vilaça 2002 para a produção do parentesco a partir dos outros).

Um jovem contava que durante uma bebedeira começou a agir como bicho atacando e assustando seus companheiros que não mais reconhecia. "Eu olhava", ele me dizia, "mas não via mais. Meu olho era outro". E, muitas vezes, enquanto algum bêbado que havia investido contra seus parentes era segurado, ele esfregava os olhos, como se tentasse enxergar melhor. $\mathrm{O}$ haklauko é um veículo privilegiado para a alteração, esta forma de experimentação de outras perspectivas que podemos resumir como devir-Outro.

Stutzman (2006) descreve as cauinagens como "bebedeiras ontologicamente comunicativas", que oferecem aos bebedores a faculdade de comunicação entre pessoas, planos cósmicos e entidades étnicas. Uma vez aberto este campo de comunicação, há várias formas possíveis de atualização para este devir-Outro em uma bebedeira de caxiri, nem todas redundando na confusão predatória e na agressão. É assim, por exemplo, que podemos entender a prevalência da música de "klaiowá" e o do uso do português pouco notado em outros contextos e mesmo pelos falantes mais incipientes - durante uma sessão de haklauko. Este devir-klaiwá pode também projetar-se como imagem de futuro e, não raro, em especial os jovens irão falar a plateias mais ou menos (des)interessadas sobre os cursos que irão fazer, os bens que irão comprar, os trabalhos que terão. A embriaguez abre também um perigoso canal de comunicação com os mortos. A saudade - ao lado da raiva e dos ciúmes - é um dos sentimentos que podem substituir a alegria. E se digo perigoso é porque os mortos são uma das figuras privilegiadas da alteridade entre os Ninam, epitomizados na forma de espíritos pole vingativos vagando pela floresta.

Há uma atração algo irresistível em direção às relações com a alteridade em que o caxiri se revela veículo eficaz, e mesmo em direção ao 
perigo destas transformações. Ficar bêbado é bom! - foi o que constataram quando experimentaram o caxiri, pela alegria que proporciona, sem dúvida, mas também justamente porque permite estas experimentações de outras perspectivas. E se os Ninam se viam às voltas com o "problema do caxiri", é preciso notar que parar de beber não era uma opção. ${ }^{8}$

O caxiri parece ser um problema para os Ninam da mesma ordem que outras alterações de perspectiva - não seria demais repetir que a metamorfose é um dos problemas centrais nas ontologias amazônicas. Se ele não pode ser suprimido - nem mesmo se se deseja fazê-lo - resta assim tentar "controlá-lo". A ideia de uma "alteração controlada" encontra eco no xamanismo e na relação que o xamã estabelece entre diversos pontos de vista, em contraposição às alterações "descontroladas" que resultam em adoecimento e morte, ou às metamorfoses míticas.

O que me parece aspecto central desta ideia seria justamente a possibilidade de reversibilidade e manutenção de certa autonomia nessas experimentações - assegurada muitas vezes pela manutenção de uma perspectiva por algumas pessoas e/ou em alguns momentos: os parentes que dizem aos ouvidos dos bêbados "não pode brigar, aqui não tem outros". É, afinal, a perspectiva destes parentes voltada para aquele que se encontra no estado limite de alteração (investindo contra seus parentes como se estes fossem inimigos), que assegura que esta transformação não seja definitiva: parentes que continuam a vê-lo e a tratá-lo como filho, irmão mais novo, irmã mais velha, ainda que o bêbado não devolva este mesmo tratamento e, ao invés, distribua socos e pontapés. Mas se todos estão bêbados como usualmente ocorre, a possibilidade de que ninguém seja capaz de assegurar a perspectiva do parentesco é real. E é aqui que o cristianismo e sua infalibilidade na manutenção da moralidade se tornam fonte privilegiada para o controle do caxiri.

Em muitas arengas sobre o caxiri era dito que os pastores pèk - os crentes - deveriam segurar a moralidade, mas poderíamos pensar que, se os pastores pek deveriam segurar a moralidade, era justamente para que outras pessoas pudessem não levá-la a sério. De fato, não parecia interessar aos Ninam que todos virassem crentes ou virassem totalmente crentes. A oposição caxiri e cristianismo era mesmo central no Alto Mucajaí.

Os Ninam, contudo, não a experimentam em termos cristãos. Ela não é vivida como um "tormento moral" (Robbins 2004) - ainda que possa ser um "problema" - e tampouco leva ao reconhecimento de si mesmos como pecadores, como desejavam os missionários. Se estes buscavam resolver a oposição entre as bebedeiras de caxiri e o cristianismo pela supressão de um dos polos - acabar com as bebedeiras convertendo-se ao cristianismo - os Ninam pareciam antes interessados em movimentar-se através dela. 
Um tal contraste surge também quando nos voltamos para o entendimento diferenciado que os missionários e os Ninam tinham sobre o conceito de conversão e sua tradução como pihi yapa lamowei.

\section{Conversão e pihi yapa lamowei}

O conceito de "conversão" - central para o cristianismo - articula explicitamente o modo como missionários formulam a relação entre "cristianismo" e "tradição/cultura". É ele o principal operador no modelo de transformação missionária, ao mesmo tempo em que sua tradução permite perceber as inflexões próprias de um modelo de transformação ninam, e as diferentes modulações da relação com a alteridade em cada um destes.

Mais do que uma adesão a um conjunto de crenças e práticas - ou uma mudança de religião - o sentido de conversão que se depreende dos testemunhos missionários é o de uma transformação pessoal e radical, que altera a vida de uma pessoa tanto em suas disposições interiores quanto em sua conduta exterior, resultado combinado da ação divina - a graça - e de uma decisão pessoal. ${ }^{9} \mathrm{O}$ modelo de suas narrativas acerca de sua própria conversão segue de perto o ideal paulino, e sua queda no caminho de Damasco como o marco de "uma profunda experiência emocional e perturbadora, que mudou a vida de Paulo completamente" (Segal 2010:11).

Complementar ao sentido oferecido por suas próprias narrativas, os missionários buscavam a fundamentação última para a tradução do conceito de conversão no próprio texto bíblico, tal como ocorre com todo conceito teológico importante, de acordo com o princípio sola sciptura. No Novo Testamento, a principal expressão utilizada para conversão é metanoia,

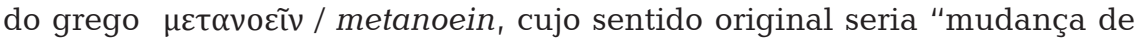
pensamento", "mudança de mente".

É por certo este sentido que os missionários buscaram traduzir para a língua ninam através da expressão pihi yapa lamowei que, de acordo com os primeiros, seria literalmente "virar completamente o pensamento", decompondo a expressão da seguinte maneira: pihi - "pensamento/cabeça"; yapa - "virar completamente"; -lamowei [verbalizadores em sua forma não flexionada]. Assim, a tradução de conversão como pihi yapa lamowei pareceria reforçar o aspecto de "decisão pessoal" da conversão ao relacioná-la ao pihi, o locus dos pensamentos e dos afetos na concepção de pessoa ninam, ao mesmo tempo em que a radicalidade desta transformação é acentuada pela ênfase que os missionários dão à tradução de yapa como

"virar completamente". 
Pihi yapa lamowei não é entretanto um neologismo, e o sentido corrente da expressão apresenta tênues, mas relevantes diferenças da exegese missionária. Quando instados a traduzi-la para o português, os Ninam apresentam formulações como "pensar outra coisa" ou "mudar de ideia", mas em nenhuma das minhas perguntas obtive espontaneamente exemplos que se referissem ao cristianismo. "Se alguém pensa 'vou pescar', depois decide 'vou pegar bacaba' ou, ainda, se pensa 'vou bater [nesta pessoa]', mas então desiste, 'não, é meu marido, deixa'... é, assim, pihi yapa lamowei", me explicava um jovem adulto que trabalhava de intérprete na Casai. A expressão é bastante utilizada no contexto de um caçador que muda de ideia quanto a que rastro seguir, e a expressão yapa, na exegese que os Ninam fizeram da expressão a meu pedido, possui o sentido de "retornar pelo caminho que se vinha", e é um dos muitos modificadores dos verbos de deslocamentos que os Ninam utilizam.

Ao falarem da relação de aceitação que alguém trava com o cristianismo - como, por exemplo, no caso da participação no batismo - os Ninam preferem dizer que tal pessoa crentelayohe (literalmente, virou crente), ou ainda mais comumente dizem que aquela pessoa "carrega a palavra de Deus", ou "segura com força a palavra de Deus" - Teus e thã hu lothoto powei - expressões que os próprios missionários reservam para traduções de "fé" e "crença". Eles terminam assim por evocar uma imagem de constância e adesão a um conjunto de valores e deixam em segundo plano o sentido de transformação radical e ruptura ensejada pelo conceito missionário de conversão.

A impressão geral é de que pihi yapa lamowei parecia capturar muito pouco da radicalidade da transformação que a conversão tem para os missionários e que eles acentuam em seus testemunhos. Se pihi é o locus das volições e dos pensamentos, é preciso notar que ele é acionado para tratar dos estados "ordinários" de consciência e, especialmente, no contexto das relações entre parentes e na ativação do "viver bem". Por mais que os missionários enfatizassem a "radicalidade" da transformação ensejada pela conversão/ pihi yapa lamowei, é justo suspeitar que os Ninam conhecem transformações muito mais radicais do que esta "mudança de ideia".

Mas esta aparente "inadequação" da expressão pihi yapa lamowei torna certamente mais relevante sua escolha no processo de tradução. Não podemos deixar de notar que cada qual das escolhas tradutivas é o resultado final - e também mais ou menos provisório - de uma tensão nem sempre explícita entre a expectativa missionária e o que os informantes e os tradutores nativos fazem com ela (Vilaça 2016:231). Se pihi yapa lamowei não diz muito sobre a experiência da conversão - ao menos não no sentido de 
conversão informado pelos testemunhos missionários - caberia nos perguntarmos em que medida este "mudar de ideia" pode ter sido sugestivo aos Ninam para pensar a relação com o cristianismo.

\section{Alternância: invenção do mundo entre o caxiri e o cristianismo}

Se a tradução de conversão por "mudar de ideia" (pihi yapalamowei) parece resultar inadequada - ao menos na perspectiva da fidelidade à noção missionária de conversão - ela se mostra, em sua traição, bastante pertinente para se refletir sobre o modo como os Ninam articulavam a experiência do cristianismo - em seu viés moralizante e em seu revés - com as bebedeiras de caxiri e seu potencial de alteração, aspectos estes de tal sorte antagonizados e entrelaçados que não parecia possível imaginar o cristianismo entre os Ninam sem levar em conta as bebedeiras de caxiri. Enquanto conversão entre os missionários diz de uma escolha irreversível entre moralidades alternativas e uma mudança de postura que tem uma direção clara e inequívoca, a imagem evocada por pihi yapa lamowei não é a de uma ruptura irreversível, mas sim a de um retorno a partir de um caminho de que se vinha, e que pode acionar um verdadeiro vaivém - da igreja pro caxiri e do caxiri pra igreja, por exemplo.

Sugiro que a tradução de conversão como pihi yapa lamowei aponta para um modo particular de coexistência entre dois conjuntos de valores e duas formas de socialidade - que encontram expressão no cristianismo e nas bebedeiras de caxiri, respectivamente, modo este dado por uma certa alternância episódica estruturada na forma de um dualismo antiestático; uma forma particular da inconstância da alma selvagem que tanto impressionou os missionários quinhentintas no contato com diversos povos tupi-guarani (Viveiros de Castro 2002b).

Diversos estudos sobre cristianismo e mudança têm se voltado para a discussão de um modelo de interconexão entre o cristianismo e o sistema cultural nativo a partir de uma relação de alternância. Barker (1990), em estudo pioneiro entre os Masin da Papua Nova Guiné, observava uma clara distinção entre a "vida na aldeia" e a "vida na missão", fazendo coincidir a alternância entre duas formas de socialidade distintas informadas pelo cristianismo ou por suas próprias tradicões com uma segmentação/ deslocamento espacial. Uma tal oscilção entre o modo de vida tradicional e o modo de vida cristão pode se realizar ainda através de movimentos coletivos de conversão e desconversão em massa, como os observados por Vilaça (2016:20) entre os Wari'. E alguns autores localizaram ainda esta 
alternância a partir de certos traços específicos, que se tornam salientes na articulação entre a tradição e o cristianismo, tal como a noção de pessoa, em um quadro de "personitude alternante" (Werbner 2011; Daswani 2011; Mosko 2010).

Se o cristianismo e o caxiri se fazem igualmente presentes entre os Ninam, a alternância que nos sugere pihi yapa lamowei refere-se sobretudo ao direcionamento das ações ninam ora na forma de coletivização e convencionalização, ora por ações diferenciantes (Wagner 2010) - em um movimento que pode assumir aqui os contornos de uma dialética entre movimentos de estabilização de uma comunidade de similares e movimentos de alteração e disrupção (ver Leite 2013; Vilaça 2016). Tanto o cristianismo quanto o caxiri conjugam diferentemente inovação e continuidade, mas o ponto que nos parece mais relevante para a aproximação de um conceito ninam de transformação é o modo como ambos são relacionados em uma mesma dialética entre forças alterantes e estabilizações moralizantes que parece constituinte da socialidade ninam.

Entre a possibilidade de constituição de uma comunidade vivendo em paz pela adesão explícita à convenção de Teus e thã e a alteração predatória e voraz propiciada pelo caxiri, mas mobilizadora de desejos, não se trata de suprimir um dos polos e nem tampouco de encontrar um equilíbrio, uma solução compósita de um e outro, um meio-termo - "beber só um pouco". A solução ninam para esta oposição é mesmo a de um dualismo antiestático: estar entre as coisas implica aqui uma alternância em que cada um dos polos desfaz parcialmente a ação do outro e cada movimento engendra também seu contrário. Os Ninam se engajam assim em contextos e modos de ação distintos e mesmo contraditórios. Ora buscando a máxima efetivação de um ideal de boa vida entre parentes e aliados a partir de ações que se referem tanto à estabilização de uma forma corporal específica quanto à afirmação de um sentido de pertencimento e comunidade - e é aqui que o cristianismo encontra o lugar entre eles, ora se engajando em ações que terminam por desfazer este "trabalho" de estabilização, ações de alteração, em que a experimentação de pontos de vista outros sobre si e sobre os seus são centrais... e as bebedeiras de caxiri são certamente o contexto privilegiado para um tal experimento.

Se é a bebida fermentada o elixir da inconstância na relação com o cristianismo, é importante notar que o mudar de ideia entre os Ninam incide também sobre a própria avaliação relativa às bebedeiras, ora festejadas, ora tratadas como um "problema". Pihi yapa lamowei, sobreposto ao contexto de relação entre o cristianismo e o caxiri, diz assim de um constante mudar de ideia, inconclusivo. Nem o modelo de alternativa 
exclusiva dos missionários - ou isto, ou aquilo - nem uma posição de hibridização - fusão consumptiva de diferenças que aqui assumiria as feições de sincretismo religioso e que é rejeitada por missionários e Ninam - a relação aqui assume a forma de alternância entre dois estados constrastivos isto e aquilo. ${ }^{10}$

Mas se a oposição entre caxiri e cristianismo pode ser entendida como uma atualização de um movimento dialético constituinte da socialidade ninam, as modulações específicas desta atualização importam. O próprio fato de o cristianismo ser incorporado e interpretado a partir das referências e dos contextos convencionais ninam, e de certa forma coincidente com a própria moralidade nativa, leva a inovações nestes contextos que devem ser consideradas com maior atenção. Uma das mais significativas, à qual já nos referimos, diz respeito ao fato de que o cristianismo se constitui como um contexto em que as convenções morais - que antes eram explicitadas ou provocadas através de um uso criativo - podem ser acionadas de forma direta e explícita como admoestações e não apenas pelos pata thepe.

No contexto da "longa conversação" estabelecida entre Ninam e missionários, o cristianismo leva ainda a uma série de transformações no modo de habitar o tempo e o espaço, bem como no entendimento sobre a corporalidade que coincidem na maior ênfase dada aos aspectos convencionalistas da ação. Os missionários introduziram uma série de aparatos para controle do tempo e do espaço e esperavam que os Ninam respondessem de acordo: os cultos obedeciam a dias e horários específicos, as trocas eram reguladas por uma racionalidade monetária e os corpos deveriam se apresentar segundo valores de "pudor" e "higiene". A disposição missionária em fazer com que os Ninam respondessem e se conformassem a regras preestabelecidas se colocava até mesmo no espaço lúdico: um dos missionários estimulava que os Ninam organizassem times de futebol e torneios amistosos. De acordo com ele, o futebol, um "jogo com regras", seria muito melhor do que a "anarquia das brincadeiras ninam".

Essas mudanças são ainda reforçadas pela própria interação com outros agentes não indígenas: funcionários da saúde, Funai, colonos assentados nas fronteiras da TIY, todos mais ou menos empenhados em esforços para convencionar. Note-se que estes espaços já estavam dados na própria dialética ninam, mas eles ganharam maior proeminência. Por mais constantes que fossem em sua inconstância, esses movimentos não são inerciais.

Os missionários traziam sua própria interpretação desse movimento de alternância e da "inconstância ninam". Eles se referiam a uma curva que haveria entre os indígenas, que estão sempre "experimentando" 
ser cristãos e depois abandonando. Mas a cada experimentação, eles diziam, o retorno não se dá para o mesmo ponto, pois algumas coisas vão se alterando.

Tem a curva - não sei se você já ouviu falar disso - que o indígena, de uma maneira geral, ele vai... e volta. Mas aí ele já não volta mais pro ponto 0 . Ele vai no 5 e volta pro ponto 2, vai no 7 e volta pro 2,5. Tem essa curva... até realmente ele achar que [o cristianismo] é uma coisa boa, né? Que ele pode segurar, pode viver por aqueles princípios e tal... (Jacqueline Santos. Entrevista, 2013)

Esta percepção missionária de um modo de transformação indígena que operaria por sucessivas aproximações evoca interpretações no campo da etnologia que percebem processos tidos muitas vezes como "aculturação", não como "perda da cultura" ou mudança social, mas como o abandono de experimentação de estados extremos da pessoa, como desenvolve Taylor (1996) a partir do abandono das experiências visionárias Arutam entre os Jivaro. Ou, ainda, como um estreitamento do campo relacional, que excluiria do movimento de alteração e interação perspectiva os animais ou outros agentes não humanos (Vilaça 2016). Em ambos os casos o resultado seria um confinamento e uma estabilização da experiência de socialidade em seus estados medianos. De certa forma, é contra um tal confinamento que o caxiri é inventado entre os Ninam, com sua possibilidade de experimentação de devires-outro sempre renovada.

Se é verdade que o cristianismo fornece um novo contexto para a realização de uma forma bem acabada da moralidade do "entre si" e da sociedade tranquila, também é fato que os Ninam empenham muito mais tempo e energia "indo atrás do caxiri" do que frequentando cultos. Se alguns Ninam podem imaginar se tornarem crentes porque bebem (e querem parar de beber) - ecoando assim o próprio discurso missionário - o contrário também poderia ser imaginado: os Ninam se embriagam para esquecer que se tornaram crentes. Estas duas afirmações não são apenas o reverso uma da outra: o modo como se concebe a relação entre cristianismo e caxiri é determinante de onde se coloca o valor de fundo em cada socialidade (Viveiros de Castro 2002a).

O que a persistência do caxiri insinua é sobretudo um certo gosto ou atração pelo perigo, inseparável da concepção de que a vida envolve um movimento contínuo e interminável de alteração, como também notava Rodgers (2002:91) entre os Ikpeng (ver também Kelly 2016:65 para a centralidade do elemento transformacional do "virar napë" entre os Yanomami). Especulamos se o caxiri não seria a vitória da guerra mesmo em tempos de paz. Mas esta já é outra história. ${ }^{11}$ 
Recebido em 26 de julho de 2018

Aprovado em: 14 de outubro de 2018

Tainah Leite

Doutora em Antropologia Social pelo PPGAS/MN e pesquisadora associada ao Laboratório de Inovações Ameríndias (LInA)/ UFRJ. Pesquisa e trabalha junto aos Ninam (Yanomami) do Mucajaí (RR) desde 2011, com especial interesse nos temas: noção de pessoa, mitologia, tradução, transformação e moralidade. 


\section{Notas}

1 Este artigo traz algumas questões trabalhadas em minha tese de doutorado defendida pelo PPGAS/MN. Versões preliminares do artigo foram apresentadas no ST Redes de Relações Indígenas, na 40ª reunião do Anpocs e no I Seminário de Inovações Ameríndias, em 2017. Agradeço a todos os participantes pelas críticas, comentários e sugestões, bem como aos membros da banca. A pesquisa de campo a partir da qual frutifica esta reflexão foi realizada sobretudo entre 2012 e 2014 e contou com o apoio do projeto "Cristianismo na Amazônia Indígena" (Edital Universal do CNPq) e dos auxílios PPGAS/MN/UFRJ (2014/1, 2012/2, 2012/1)

2 O Mucajaí e o Palimi-ú são citados como pontos de origem do "caxiri", que tem se espalhado por algumas regiões da TIY (ver Machado 2015). Faço saber, contudo, que os missionários apresentam versões diferentes da introdução do caxiri, atribuindo-a à relação com os Macuxi em estadias na Casai, em Boa Vista, e sinalizam que a cronologia de abertura do posto do Palimi-ú não coincide com os primeiros registros de uso da bebida entre os Ninam.

3 Utilizarei o itálico sublinhado para expressões em português empregadas pelos Ninam de maneira a destacar o uso criativo que eles podem fazer desta língua e evitar um entendimento muito aplainado de algumas delas.

4 Utilizo a expressão "dialética entre modos de ação" de maneira a ressaltar a influência que tem para esta leitura da relação caxiri e cristianismo entre os Ninam o modelo de ações diferenciantes e convencionalziantes proposto por Wagner (2010) e que tem se mostrado bastante produtivo e pertinente para se pensarem as formas e os devires de socialidade da Amazônia, em sua duplicidade (Viveiros de Castro 2002a; Coelho de Souza 2010, 2017; Vilaça 2016), com especial rendimento nas etnografias yanomami (Kelly 2005, 2016; Leite 2013).

5 A expressão para a ideia de pecado é paluk inxi, que pode ser traduzida como "peito sujo". Paluk - o interior da cavidade toráxica - é considerada a sede das volições e dos pensamentos por parte dos Ninam. Os missionários algumas vezes traduzem por "coração".

6 Os aspectos cosmológicos do cristianismo, incorporados ao escopo de conhecimento dos xamãs, são de certa forma englobados pelo próprio xamanismo - dando-se a conhecer pela mediação do xamã e seus espíritos auxiliares. Teus utupë [a imagem/ espírito de Teus para os Ninam; o Espírito Santo para os missionários] é vertido na chave da multiplicidade e feito imanente. Do mesmo modo, a escatologia cristã tem pouca relevância na vida prática ninam: o céu não se apresenta como alternativa privilegiada para o destino post-mortem, ao mesmo tempo em que o inferno - e o temor de para lá ser enviado - tampouco mobiliza efetivamente os Ninam. Ao fim, as relações entre os cristãos parecem importar tanto ou mais do que a relação com Deus. Note-se que este tratamento do cristianismo como sistema ético-moral, antes mesmo que mágico-religioso, é comum em diversas etnografias. 
7 Este parece ser um traço comum dos encontros alcoólicos na Amazônia. Ver também, dentre outros, Viveiros de Castro (1986:267) para o fato de as festas de cauim serem o ponto máximo de concentração Araweté e momento culminante da sociabilidade. Cf. Rivière (2000) para uma bela análise das bebedeiras entre os Trio que aponta para esta mesma direção.

8 No caminho de franca experimentação com estes dois elementos em que se encontram os Ninam, esta era uma questão complexa e sobre a qual havia várias e divergentes posições. Um dos grandes conflitos girava em torno da questão dos festivais funerários. Algumas pessoas sugeriam que não deveriam mais guardar as cinzas para então não serem mais obrigados a realizar festas e assim não beberem. A radicalidade da opção era rejeitada por muitos que alegavam que as "cinzas eram cultura mesmo" e que, portanto, eles não poderiam abandoná-la. A opção de realizar os festivais sem o haklauko - como os antigos - oferecida pelos missionários era rapidamente descartada. A justificativa apresentada pelos Ninam era a de que "agora que conheciam as festas com caxiri" não podiam mais fazer sem. Em conversas recentes por telefone com meus anfitriões entre os Ninam, fui informada que no Polapi eles "acabaram mesmo com o caxiri".

9 Há uma vasta bibliografia sobre o tema da conversão que desperta interesse em diversos campos de conhecimento (antropologia, psicologia, teologia etc.). Aqui, entretanto, atenho-me à conceitualização de conversão a partir dos testemunhos missionários. Estes testemunhos conformam um estilo narrativo característico (Dullo \& Duarte 2016), cumprindo um papel decisivo na própria definição do sentido de conversão no interior de uma comunidade de crentes. Como nota Segal (2010, p. 44s), "um relato de conversão idealiza e convenciona a experiência de conversão a partir do grupo que a valoriza, guiando convertidos em potencial".

10 Certamente, o descrito para os Ninam encontra eco na posição antimestiçagem descrita por Kelly (2016; ver também 2013) para a questão de virar branco entre os Yanomami do Ocamo. Em seu trabalho, o autor opõe esta posição antimestiçagem a um processo de hibridização do tipo nem isto, nem aquilo da posição criolla - modelo de transformação vigente no discurso latino-americano. Aqui a posição missionária rejeita esta possível hibridização, entendida como sincretismo religioso, que pode ser descrito como um ou isto ou aquilo. Este duplo contraste parece reforçar ainda mais a relevância e a singularidade do operador e,e para se pensar um modelo amazônico de transformação.

11 Diferentes versões de bebidas fermentadas têm se espalhado pela TIY, em uma dinâmica de imitação/diferenciação que conecta os Ninam a outros grupos Yanomami. Não por acaso, esta inovação é frequentemente tratada como um "problema" - por lideranças políticas indígenas, representantes das frentes indigenistas e dos órgãos governamentais - e talvez possa se estender à pertinência da hipótese avançada aqui sobre o caxiri encontrar seu lugar na tensão com instâncias moralizantes/convencionalizantes. Escola, políticas de saúde pública e missões cristãs, a tríade klaiowa/nape, com que lidam cotidianamente os Ninam/ Yanomami coincidem quanto à grande ênfase dada não apenas ao maior con- 
vencionalismo, mas, sobretudo, à pacificação e ao reforço de um suposto sentido de comunidade. Em que pese a especificidade da presença missionária entre os Ninam, talvez seja possível vislumbrar semelhante dialética em que o caxiri se apresenta como linha de fuga para estes outros movimentos e contextos mais ou menos convencionalizantes. 


\section{Referências bibliográficas}

ALÈS, Catherine. 2006. "La colère comme marqueur d'amour. Éthique de la convivialité". In: Yanomami: l'ire et le désir. Paris: Ed. Karthala. pp. 161-181.

BARKER, John. 1990. "Mission Station and Village: Religious Practice and Representations in Maisin Society". In: __-, Christianity in Oceania: Ethnographic Perspectives. Lanham, Md.: University Press of America. pp. 173-196.

CANNELL, Fenella. 2005. "The Christianity of Anthropology". Journal of the Royal Anthropological Institute, 11 (2):335-56. Disponível em: https://doi.org/10.1111/j.14679655.2005.00239.x.

CARNEIRO DA CUNHA, Manuela. 2009. "'Cultura' e cultura: conhecimentos tradicionais e direitos intelectuais". In: Cultura com aspas e outros ensaios. São Paulo: Cosac Naif. pp. 311-374.

CARRERA, Javier. 2004. The fertility of words: as pects of language and sociality among Yanomami people of Venezuela. Tese de Doutorado, Univeristy of St. Andrews.

COELHO DE SOUZA, Marcela. 2010. "A vida material das coisas intangíveis". In: E. C. Lima \& M. S. Coelho de Souza, Conhecimento e cultura: práticas de transformação no mundo indígena. Brasília: Athalaia Editora.

COMAROFF, Jean \& COMAROFF; John. 1997. Of Revelation and Revolution. Vol. 2: The dialectics of modernity on a South African frontier. Chicago and London: The University of Chicago Press.

DULLO, Eduardo \& DUARTE, Luiz Fernando Dias. 2016. "Introdução. Dossiê testemunhos". Religião \& Sociedade, 36 (2):12-18. Dis- ponível em: https://dx.doi.org/ 10.1590/0100-85872016v36n2cap01

ENGELKE, Matthew. 2004. "Discontinuity and the Discourse of Conversion". Journal of Religion in Africa 34 (1):82109. Disponível em: https://doi. org/10.1163/ 157006604323056732.

FAUSTO, Carlos. 2007. "If God were a jaguar: cannibalism and Christianity among the Guarani (16th-20th Centuries). In: Carlos Fausto \& Michael Heckenberger (eds.), Time and memory in Indigenous Amazonia. Anthropological Perspectives. Florida: University Press of Florida. pp. 74-105. GOW, Peter. 2001. An Amazonian Myth and its History. Oxford: Oxford University Press.

2006. "Forgetting conversion. The Summer Institute of Linguistic mission in the Piro lived world". In: Fenella Cannell (ed.), The Anthropology of Christianity. Durham \& London: Duke University Press. pp. 211-239.

KELLY, José Antonio. 2016. Sobre a antimestiçagem. Florianópolis: Cultura e Barbárie.

. 2005. "Notas para uma teoria do 'virar branco'". Mana, 11 (1):201-34. Disponível em: https://doi.org/10.1590/ S0104-93132005000100007.

LE TORNEAU, François-Michel. 2003. "Colonização agrícola e áreas protegidas no Oeste de Roraima". In: Bruce Albert (ed.), Fronteira agropecuária e Terra Indígena Yanomami em Roraima. Documentos Yanomami n. 3. Brasília, Boa Vista: CCPY.

LEITE, Tainah Víctor Silva. 2013. "Imagens da humanidade: metamorfose e moralidade na mitologia Yanomami". Mana, Rio de Janeiro, v. 19, n. 1:69-97. Disponível em: <http://www. scielo.br/scielo.php?script=sci_artte xt\&pid $=$ S0104-93132013000100003 
$\& \mathrm{lng}=\mathrm{e} n \& \mathrm{n} \mathrm{rm}=\mathrm{i} \mathrm{s}$ o $>$. Acesso em $29 / 10 / 2018$. LÉVI-STRAUSS, Claude. 1993. História de Lince. São Paulo: Cia das Letras.

MACHADO, Ana Maria. 2015. "LUTAMU": Relações interétnicas e protagonismo feminino no Papiu no contexto de um conflito intercomunitário Yanomami. Dissertação de Mestrado, UFSC.

MEYER, Birgit. 1998. "'Make a Complete Break with the past'. Memory and Post-Colonial Modernity in Ghanaian Pentecostalist Discourse". Journal of Religion in Africa, 28 (3):316-49. Disponível em: https:// doi.org/10.2307/1581573.

MOSKO, Mark. 2010. "Partible Penitents: Dividual Personhood and Christian Practice in Melanesia and the West". Journal of the Royal Anthropological Institute, 16 (2): 215-240.

OVERING, Joanna. 1999. "Elogio do cotidiano: a confiança e a arte da vida social em uma comunidade amazônica". Mana, 5 (1):81-107. Disponível em: https://doi.org/10.1590/S010493131999000100004.

OVERING, Joanna \& PASSES, Alan. 2000. "Introduction". In: (eds.), The Anthropology of Love and Anger. The aesthetics of conviviality in $\mathrm{Na}$ tive Amazonia. London: Routledge.

RIVIĖRE, Peter. 2000." 'The more we are together...'". In: Joanna Overing \& Alan Passes (eds.). The Anthropology of Love and Anger. The aesthetics of conviviality in Native Amazonia. London \& New York: Routledge. pp. 252-267.

ROBBINS, Joel. 2004. Becoming sinners. Christianity and moral torment in a Papua New Guinea Society. Berkeley, Los Angeles, London: University of California Press.
2007. "Continuity Thinking and the Problem of Christian Culture". Current Anthropology, 48 (1):5-38.

RODGERS, David. 2002. "A soma anômala: a questão do suplemento no xamanismo e menstruação Ikpeng". Mana, 8 (2):91-125. Disponível em: https://doi.org/10.1590/ S010493132002000200004.

SANTOS, Jaqueline \& MONTES, Rosa. 2011. "'Linha Cruzada' na comunicação do evangelho ao povo Ninam do Alto Rio Mucajaí". Antropos: Revista de antropologia, 4 (5):126-152. SEGAL, Alan. 2010. Paulo, o convertido. Apostolado e apostasia de Saulo o fariseu. São Paulo: Ed. Paulus. SZTUTMAN, Renato. 2006. De outros caxiris: festa, embriaguez e comunicação na Amazônia indígena. Dissertação de Mestrado, USP [versão para publicação].

TAYLOR, Anne-Christine. 1996. "The soul's body and its states: an Amazonian perspective on the nature of being human". Journal of the Royal Anthropological Institute (N.S.), 2:201-215.

VANZOLINI, Marina. 2015. A flecha dos ciúmes: o parentesco e seu avesso segundo os Aweti do Alto Xingu. São Paulo: Terceiro Nome.

VILAÇA, Aparecida. 2002. "Making kin out of others in Amazonia". Journal of the Royal Anthropological Institute (N.S.), 8:347-365. .2016. Praying and Preying: Christianity in Indigenous Amazonia (The Anthropology of Christianity). Berkeley: University of California Press.

VIVEIROS DE CASTRO, Eduardo. 1986. Araweté: os deuses canibais. Rio de Janeiro: AnpocS/Jorge Zahar Editor. . 2002a . "Atualização e contraefetuação do virtual: o processo do parentesco". In: , A inconstância da alma selvagem e outros ensaios de 
Antropologia. São Paulo: Cosac Naify. pp. 401-456.

. 2002b. "O mármore e a murta: sobre a inconstância da alma selvagem". In: A inconstância da alma selvagem e outros ensaios de Antropologia. São Paulo: Cosac Naify. pp. 181-264.

. 2012. "'Transformação' na antropologia, transformação da 'antro- pologia'". Mana, 18 (1):151-71. Disponível em: https://doi.org/10.1590/ S0104-93132012000100006.

WAGNER, Roy. 2010 [1975]. A invenção da cultura. São Paulo: Cosac Naify. WERBNER, Richard. 2011. "The Charismatic Dividual and the Sacred Self". Journal of Religion in Africa, 41:180-205. 


\section{MUDANDO DE IDEIA: CRISTIANISMO EVANGÉLICO E FESTAS DE CAXIRI ENTRE OS NINAM DO ALTO MUCAJAí}

\begin{abstract}
Resumo
Este artigo busca destacar alguns elementos para o entendimento de um modelo de transformação ninam a partir da relação que estes estabelecem atualmente com o cristianismo evangélico e as festas de caxiri. O argumento central explora como estas duas vias de transformação percorridas pelos Ninam - as bebedeiras de caxiri e o cristianismo, cada qual articulando à sua maneira continuidade e mudança - são relacionadas em uma mesma estrutura que informaria um modo característico de experimentar e criar um mundo continuamente transformacional. Ao mesmo tempo busca-se uma comparação com o modelo de transformação missionário (a conversão) de maneira a acentuar os traços distintivos do modo indígena de transformação. A trama que conecta cristianismo e bebedeiras de caxiri, Ninam e missionários é assim o enredo privilegiado para vislumbrar dois modelos diferenciados de transformação em relação.

Palavras-chave: Ninam (Yanomami), transformação, cristianismo, crise.
\end{abstract}

\section{CHANGE OF MIND: EVANGELICAL CHRISTIANITY AND CAXIRI PARTIES AMONG THE NINAM DEL ALTO MUCAJAí}

\begin{abstract}
This article reveals a Ninam model of transformation by engaging their contemporary relations with Evangelical Christianity and the caxiri beer-feasts. It explores how these two paths of transformation - caxiri drunkenness and Evangelical Christianity, each of which articulates, in its own way, continuity with change - are related within the same structure that manifests a characteristic way of experiencing and creating a world in continuous transformation. At the same time, this model is compared with the missionary model of transformation (conversion), in order to accentuate the distinctive features of the Indigenous mode of transformation. The web that connects Christianity and drunkenness, Ninam and missionaries, is thus a privileged stage for envisaging two differentiated models of transformation in relation with each other.
\end{abstract}

Keywords: Ninam (Yanomami); transformation; christianity; crisis. 


\section{CAMBIANDO DE IDEA:}

\section{CRISTIANISMO EVANGÉLICO Y FIESTAS DE CAXIRI ENTRE LOS NINAM DEL ALTO MUCAJAÍ}

\section{Resumen}

Este artículo busca destacar algunos elementos para el entendimiento de un modelo de transformación ninam a partir de la relación que ellos establecen actualmente con el cristianismo evangélico y las fiestas de caxiri. El argumento central explora como estas dos vías de transformación recorridas por los Ninam -las borracheras de caxiri y el cristianismo, cada cual articulando a su manera continuidad y cambio- están relacionadas en una misma estructura que revela un modo característico de experimentar y crear un mundo continuamente transformacional. Al mismo tiempo se busca una comparación con el modelo de transformación misionero (la conversión) de manera a acentuar los rasgos distintivos del modo indígena de transformación. La trama que conecta cristianismo y borracheras de caxiri, Ninam y misioneros es así el argumento privilegiado para vislumbrar dos modelos diferenciados de transformación en relación.

Palablas clave: Ninam (Yanomami), Cristianismo, transformación, crisis. 